\title{
Value of Left Atrial Function in Predicting Exercise Capacity in Heart Failure With Moderate to Severe Left Ventricular Systolic Dysfunction
}

\author{
Sait TerZI, ${ }^{1}$ MD, Sennur Unal DAYI, ${ }^{1}$ MD, Tamer AKbulut,${ }^{1}$ MD, \\ Nurten SAYAR, ${ }^{1} \mathrm{MD}$, Tuba BILSEL, ${ }^{1} \mathrm{MD}$, Burak TANGUREK, ${ }^{1} \mathrm{MD}$, \\ Haldun AKGOZ, ${ }^{1} \mathrm{MD}$, Hacer Kose, ${ }^{2} \mathrm{MD}$, Serdar YILMAZER, ${ }^{1} \mathrm{MD}$, \\ and Kemal YeSILCIMEN, ${ }^{1} \mathrm{MD}$
}

\section{SUMMARY}

Left atrial (LA) function is associated with left ventricular (LV) diastolic filling and cardiac output response to exercise. But the relation between LA function and exercise performance has not been adequately evaluated.

The aim of this study was to investigate the relation between LA function and exercise capacity in dilated cardiomyopathy (DCM) with cardiopulmonary exercise testing.

Forty-four patients with a left ventricular end-diastolic dimension (LVDd) $\geq 60 \mathrm{~mm}$ and an ejection fraction $(E F) \leq 40 \%$, and in normal sinus rhythm were included in this study. Patients were divided into group 1 and group 2 according to their exercise peak oxygen uptake $\left(\dot{\mathrm{VO}}_{2}\right.$ ) (group 1: peak $\dot{\mathrm{VO}}_{2}>14 \mathrm{~mL} / \mathrm{kg} / \mathrm{min}$, group 2: peak $\dot{\mathrm{V}}_{2} \leq 14 \mathrm{~mL}$ / $\mathrm{kg} / \mathrm{min}$ ). LA function indices were defined as follows: LA end-systolic diameter (LASd), end-diastolic diameter (LADd), LA systolic volume (LASV), LA diastolic volume (LADV), LA ejection volume (LAEV), and LA ejection fraction (LAEF).

LASd, LADd, LASV, and LADV were significantly increased in group $2(P<0.001$, $P<0.001, P<0.05, P<0.005)$. Group 1 had significantly higher LAEF $(P<0.001)$ and LVEF $(P<0.05)$. Group 2 had significantly shorter exercise duration, and decreased anaerobic threshold levels and minute ventilation volumes $(P<0.001, P<0.001, P<$ 0.005 ). There was a positive correlation between peak $\mathrm{VO}_{2}$ and $\mathrm{LVEF}(\mathrm{r}=0.46, P=$ $0.002)$, and LAEF ( $\mathrm{r}=0.61, P<0.001)$, peak A wave velocity $(\mathrm{r}=0.39, P=0.009)$, E wave deceleration time $(\mathrm{r}=0.56, P<0.001)$, and isovolumic relaxation time (IVRT) $(\mathrm{r}$ $=0.35, P=0.04)$. There was a negative correlation between peak $\mathrm{VO}_{2}$ and LASd $(\mathrm{r}=$ $-0.53, P<0.001)$ LADd $(\mathrm{r}=-0.59, P<0.001)$, LASVI $(\mathrm{r}=-0.34, P=0.027)$, LADVI $(\mathrm{r}$ $=-0.37, P=0.001)$, and the $\mathrm{E} / \mathrm{A}$ ratio $(\mathrm{r}=-0.41, P=0.006)$,

Decreased LAEF and increased LA sizes were associated with decreased peak $\mathrm{VO}_{2}$. The results clearly demonstrate that LA functions at rest are related to exercise performance in patients with heart failure. (Int Heart J 2005; 46: 123-131)

Key words: Heart failure, Left atrial function, Cardiopulmonary exercise test

From the ${ }^{1}$ Siyami Ersek Cardiovascular Hospital and Research Center, and ${ }^{2}$ Internal Medicine Department, Haydarpasa Numune Hospital, Istanbul, Turkey.

Address for correspondence: Sait Terzi, MD, Siyami Ersek Cardiovascular Hospital and Research Center, Emniyet Mah,

Yasardogu Sok, No:3/1, Uskudar, Istanbul, Turkey.

Received for publication May 24, 2004.

Revised and accepted August 6, 2004. 
EXERCISE intolerance is one of the main symptoms of congestive heart failure (CHF), but the mechanisms responsible for limiting exercise capacity have not been completely clarified. Atrial fibrillation (AF) is associated with a reduced exercise capacity. However, exercise intolerance in patients with AF is related more to the underlying heart disease than to AF itself. ${ }^{1)}$ Previous studies have demonstrated that left ventricular (LV) systolic function does not predict exercise capacity. ${ }^{2,3)}$ In contrast, recent reports showed that LV diastolic dysfunction was intimately related to functional status. ${ }^{4,5)}$ Although LV diastolic dysfunction is known to reduce exercise capacity, it is often difficult to predict precise exercise capacity by evaluating diastolic filling because hemodynamic parameters measured at rest are influenced by age, heart rate, loading condition, and the properties of the LV and left atria (LA). LA function is closely related to LV diastolic filling, therefore, indices of LA function may predict exercise capacity in patients with LV dysfunction. ${ }^{6-8)}$ LA volume and antero-posterior diameter measurements have been used for the evaluation of left atrial function. ${ }^{9,10)}$ The objective of the present study was to evaluate the correlation between LA function and exercise capacity in patients with heart failure.

\section{Methods}

This study was approved by the ethics committees of the participating hospitals. Subjects that gave informed consent were included in the study. Patients referred for echocardiographic evaluation who fullfilled the inclusion criteria were recruited consecutively. Coronary angiography and myocardial perfusion scintigraphy were conducted according to the discretion of the primary physician.

The study population consisted of 44 consecutive patients (34 males, 10 females, mean age, $58 \pm 10$ ) with LV systolic dysfunction, which was defined as an M-mode echocardiographic LV end diastolic diameter $\geq 60 \mathrm{~mm}$ and an ejection fraction $\leq 40 \%$, and in normal sinus rhythm. Patients with atrial fibrillation, chronic obstructive pulmonary disease, valvular heart disease, and exerciseinduced myocardial ischemia, or other noncardiac conditions limiting exercise capacity were excluded.

Echocardiography: Echocardiography was conducted with a Hewlett-Packard Sonos 1500 echocardiograph (Andover, Massachusetts, USA) and a $2.5 \mathrm{MHz}$ transducer. M-mode echocardiographic measurements were obtained from the left parasternal window and measurements were made according to the recommendations of the American Society of Echocardiography. ${ }^{11)} \mathrm{LV}$ volumes and ejection fractions were measured by apical two and four-chamber views using the modified Simpson method. ${ }^{12)}$ In order to evaluate LV diastolic filling dynamics, the pulsed wave sample volume was set between the tips of the mitral leaflets in 
the apical four-chamber view. Maximal early " $E$ " and late " $A$ " filling velocities, the E/A ratio, deceleration time of the "E" wave velocity, and IVRT were measured. ${ }^{4)}$ LA antero-posterior diameters were determined using a parasternal longaxis window. LA systolic diameter (LASd) (maximal LA dimension) was measured at the end of the T wave and LA diastolic diameter (LADd) (minimal LA dimension) was measured at the beginning of the QRS complex on the electrocardiograph. LA volumes were measured from apical four-chamber and two-chamber views. Volume determinations were calculated using a "biplane area-length" method. The LA systolic volume (LASV; maximal LA volume) was determined when the mitral leaflets had just opened at the end of systole. LA diastolic volume (LADV; minimal LA volume) was determined when the mitral leaflets had just closed at the end of diastole. Total LA reservoir function was determined by measuring LA ejection volume $(\mathrm{LAEV})=\mathrm{LASV}-\mathrm{LADV}$ and global LA function by measuring LA ejection fraction $(\mathrm{LAEF})=\mathrm{LAEV} / \mathrm{LASV}{ }^{8}{ }^{8}$

Cardiopulmonary exercise testing: Cardiopulmonary exercise testing was performed with a Quinton 5000 Treadmill Exercise apparatus (Terry Avenue, Seattle, USA) and a Cortex 3B apparatus (Nonnenstrasse, Leipzry, Germany) by measuring breath-by-breath $\mathrm{O}_{2}$ uptake and $\mathrm{CO}_{2}$ production. ${ }^{13)}$ Volume and gas calibrations were conducted before performing each test. Exercise testing was started at a constant speed of $1.7 \mathrm{~km} / \mathrm{h}$ and a grade of zero, with $2 \%$ further increments in grade per minute until the patient was limited by complaints of shortness of breath, fatigue, or chest discomfort. The anaerobic threshold was determined by the V-slope method. Exercise capacity was evaluated by measuring the following parameters: peak oxygen uptake $\left(\dot{\mathrm{VO}}_{2}\right), \dot{\mathrm{VO}}_{2}$-AT, (oxygen uptake at anaerobic threshold), VE, (minute ventilation), and peak exercise duration. Patients were divided into two groups according to their exercise capacity: group I: mild-tomoderate exercise intolerance (peak $\dot{\mathrm{VO}}_{2}>14 \mathrm{~mL} / \mathrm{kg} / \mathrm{min}$ ); group II: severe exercise intolerance (peak $\mathrm{V}_{2} \leq 14 \mathrm{~mL} / \mathrm{kg} / \mathrm{min}$ ).

Statistical analysis: All values are expressed as the mean \pm standard deviation. Student's $t$ test was used to compare continuous variables and the chi-squared test to compare categorical variables. To determine the relation between echocardiographic parameters and exercise capacity, linear regression analysis was performed. $P$ values less than 0.05 were considered significant.

\section{RESULTS}

Of the 44 patients enrolled in the study, 30 had ischemic cardiomyopathy (ICM) and 14 had idiopathic dilated cardiomyopathy (DCM). Thirty-one patients were in New York Heart Association (NYHA) functional class I-II, and 13 patients were in class III. 
The baseline characteristic and cardiopulmonary exercise test parameters are summarised in Table I. Group 2 had a higher NYHA class, lower exercise capacity, shorter exercise time, lower anaerobic threshold, and lower minute-ventilation volumes. The echocardiographic parameters are presented in Table II.

Table I. Baseline Characteristics and Cardiopulmonary Exercise Test Parameters of Study Population

\begin{tabular}{lcc}
\hline & Group 1 (peak $\left.\dot{\mathrm{V}}_{2}>14 \mathrm{~mL} / \mathrm{kg} / \mathrm{min}\right)$ & Group 2 (peak $\left.\dot{\mathrm{o}}_{2} 14 \leq \mathrm{mL} / \mathrm{kg} / \mathrm{min}\right)$ \\
\hline Number & 21 & 23 \\
Age & $55 \pm 10$ & $61 \pm 10$ \\
Male/Female & $18 / 3$ & $16 / 7$ \\
NYHA class & & \\
I & 8 & 0 \\
II & 10 & 13 \\
III & 3 & 10 \\
Peak heart rate & $148 \pm 21$ & $139 \pm 18$ \\
Exercise duration $(\mathrm{min})$ & $11.0 \pm 4$ & $5.60 \pm 2.1^{* * *}$ \\
Peak $\dot{\mathrm{V}} \mathrm{O}_{2}(\mathrm{~mL} / \mathrm{kg} / \mathrm{min})$ & $19.6 \pm 4.1$ & $11.1 \pm 1.8^{* * *}$ \\
Peak $\dot{\mathrm{V}} \mathrm{O}_{2}(\mathrm{~L} / \mathrm{min})$ & $1.40 \pm 0.36$ & $0.76 \pm 0.16 * * *$ \\
Peak $\dot{\mathrm{V} C O}(\mathrm{~L} / \mathrm{min})$ & $1.30 \pm 0.35$ & $0.76 \pm 0.21 * * *$ \\
Peak VE $(\mathrm{L} / \mathrm{min})$ & $46 \pm 12$ & $30 \pm 8^{* * *}$ \\
RER & $1.12 \pm 0.14$ & $1.08 \pm 0.19$ \\
AT $(\mathrm{mL} / \mathrm{kg} / \mathrm{min})$ & $11.0 \pm 2.9$ & $6.7 \pm 1.7^{* * *}$ \\
\hline
\end{tabular}

$* P<0.05, * * P<0.005, * * * P<0.001$

peak $\dot{\mathrm{V}}_{2}=$ peak oxygen uptake; $\mathrm{VE}=$ peak minute ventilation at peak exercise; $\mathrm{RER}\left(\mathrm{VCO}_{2} / \mathrm{V}_{2}\right)=$ respiratory exchange ratio; $\mathrm{AT}=$ anaerobic threshold.

Table II. LV and LA Function Indices in Heart Failure Categorized According to Peak Oxygen Uptake

\begin{tabular}{lcc}
\hline & Group 1 (peak $\left.\dot{\mathrm{V}} \mathrm{O}_{2}>14 \mathrm{~mL} / \mathrm{kg} / \mathrm{min}\right)$ & Group 2 (peak $\left.\dot{\mathrm{V}} \mathrm{O}_{2} \leq 14 \mathrm{~mL} / \mathrm{kg} / \mathrm{min}\right)$ \\
\hline NYHA class & $2.1 \pm 0.3$ & $2.5 \pm 0.5^{* * *}$ \\
LVSd $(\mathrm{mm})$ & $56 \pm 5$ & $58 \pm 8$ \\
LVDd $(\mathrm{mm})$ & $66 \pm 4$ & $69 \pm 7$ \\
LVSVI $\left(\mathrm{mL} / \mathrm{m}^{2}\right)$ & $103 \pm 20$ & $119 \pm 27^{*}$ \\
LVDVI $\left(\mathrm{mL} / \mathrm{m}^{2}\right)$ & $157 \pm 26$ & $171 \pm 30$ \\
LVEF $(\%)$ & $0.35 \pm 0.8$ & $0.27 \pm 0.5^{*}$ \\
Peak E wave velocity $(\mathrm{cm} / \mathrm{sec})$ & $66 \pm 23$ & $80 \pm 30$ \\
Peak A wave velocity $(\mathrm{cm} / \mathrm{sec})$ & $68 \pm 21$ & $58 \pm 20$ \\
E/A ratio & $1.05 \pm 0.5$ & $1.60 \pm 0.9$ \\
IVRT $(\mathrm{ms})$ & $161 \pm 42$ & $124 \pm 28^{*}$ \\
DT $(\mathrm{ms})$ & $288 \pm 69$ & $173 \pm 54^{* * *}$ \\
LADd $(\mathrm{mm})$ & $32 \pm 8$ & $41 \pm 5^{* * *}$ \\
LASd $(\mathrm{mm})$ & $41 \pm 6$ & $47 \pm 4^{* * *}$ \\
LASVI $\left(\mathrm{mL} / \mathrm{m}^{2}\right)$ & $39 \pm 16$ & $53 \pm 13^{*}$ \\
LADVI $\left(\mathrm{mL} / \mathrm{m}^{2}\right)$ & $20 \pm 10$ & $34 \pm 17^{* *}$ \\
LAEF $(\%)$ & $0.50 \pm 0.10$ & $0.27 \pm 0.12^{* * *}$ \\
\hline
\end{tabular}

$* P<0.05, * * P<0.005, * * * P<0.001$

LVSd = left ventricular systolic diameter; $L V D d=$ left ventricular end-diastolic diameter; LVSVI = left ventricular systolic volume index; LVDVI = left ventricular end-diastolic volume index; LVEF = left ventricular ejection fraction; IVRT = isovolumetric relaxation time; DT = deceleration time; LADd = left atrial end-diastolic diameter; LASd = left atrial systolic diameter; LASVI = left atrial systolic volume index (LAV max/BSA); LADVI = left atrial end-diastolic volume index (LAV min/BSA); LAEF = left atrial ejection fraction; BSA = body surface area. 
Group 2 had lower LVEF $(0.27 \pm 0.5$ versus $0.35 \pm 0.8)$, higher LADd $(41 \pm 5$ versus $32 \pm 8 \mathrm{~mm}$ ), LASd (47 \pm 4 versus $41 \pm 6 \mathrm{~mm}$ ), LADVI (34 \pm 17 versus 20 $\left.\pm 10 \mathrm{~mL} / \mathrm{m}^{2}\right)$ and LASVI $\left(53 \pm 13\right.$ versus $\left.39 \pm 16 \mathrm{~mL} / \mathrm{m}^{2}\right)$, lower LAEF $(0.27 \pm$ 0.12 versus $0.50 \pm 0.10)$, a faster peak E velocity $(80 \pm 30$ versus $66 \pm 23 \mathrm{~cm} / \mathrm{sec}$ ), a higher E/A ratio (1.60 \pm 0.9 versus $1.05 \pm 0.5)$, shorter deceleration time of the E velocity (173 \pm 54 versus $288 \pm 69 \mathrm{~ms})$, and a shorter IVRT (124 \pm 28 versus $161 \pm 42 \mathrm{~ms})$.

The relationships between peak $\dot{\mathrm{V}}_{2}$ and echocardiographic parameters are shown in Table III. Univariate regression analysis revealed that peak $\dot{\mathrm{V}} \mathrm{O}_{2}$ was significantly correlated with the LAEF $(\mathrm{r}=0.61, P<0.001), \mathrm{LASd}(\mathrm{r}=-0.53, P$ $<0.001)$, LADd $(\mathrm{r}=-0.59, P<0.001)$, LASVI $(\mathrm{r}=-0.34, P=0.027)$, and LADVI ( $\mathrm{r}=-0.37, P<0.001)$. There was also a correlation between peak oxygen uptake and peak A wave velocity $(\mathrm{r}=0.39, P=0.009)$, the $\mathrm{E} / \mathrm{A}$ ratio $(\mathrm{r}=-0.41, P=$ $0.006)$, the peak E velocity deceleration time $(\mathrm{r}=0.56, P<0.001)$, and IVRT ( $\mathrm{r}=$ $0.35, P=0.04)$. The LV end-diastolic and end-systolic dimensions were not cor-

Table III. Univariate Analysis of Echocardiographic Parameters in Heart Failure

\begin{tabular}{lcc}
\hline & $\mathrm{r}$ & $P$ \\
\hline LVSd $(\mathrm{mm})$ & -0.11 & 0.56 \\
LVDd $(\mathrm{mm})$ & -0.08 & 0.59 \\
LVSVI $\left(\mathrm{mL} / \mathrm{m}^{2}\right)$ & -0.29 & 0.07 \\
LVDVI $\left(\mathrm{mL} / \mathrm{m}^{2}\right)$ & -0.11 & 0.48 \\
LVEF $(\%)$ & 0.46 & 0.002 \\
Peak E wave velocity $(\mathrm{cm} / \mathrm{sec})$ & -0.16 & 0.29 \\
Peak A wave velocity $(\mathrm{cm} / \mathrm{sec})$ & 0.39 & 0.009 \\
E/A ratio & -0.41 & 0.006 \\
IVRT $(\mathrm{ms})$ & 0.35 & 0.04 \\
DT $(\mathrm{ms})$ & 0.56 & $<0.001$ \\
LADd $(\mathrm{mm})$ & -0.59 & $<0.001$ \\
LASd $(\mathrm{mm})$ & -0.53 & $<0.001$ \\
LASVI $\left(\mathrm{mL} / \mathrm{m}^{2}\right)$ & -0.34 & 0.027 \\
LADVI $\left(\mathrm{mL} / \mathrm{m}^{2}\right)$ & -0.37 & 0.01 \\
LAEF $(\%)$ & 0.61 & $<0.001$ \\
\hline LVSd $=1 \mathrm{cft}$ & & \\
\hline
\end{tabular}

LVSd = left ventricular systolic diameter; LVDd = left ventricular end-diastolic diameter; LVSVI = left ventricular systolic volume index; LVDVI = left ventricular enddiastolic volume index; LVEF = left ventricular ejection fraction; IVRT $=$ isovolumetric relaxation time ; DT = deceleration time ; LADd = left atrial end-diastolic diameter; LASd = left atrial systolic diameter; LASVI = left atrial systolic volume index (LASV/BSA); LADVI = left atrial end-diastolic volume index (LADV/BSA); LAEF = left atrial ejection fraction; BSA = body surface area. 
related with peak oxygen uptake. However, LV ejection fraction was related to peak $\mathrm{VO}_{2}(\mathrm{r}=0.46, P=0.002)$.

\section{DISCUSSION}

The results of the present study demonstrate that LA function at rest is associated with exercise performance in ICM and DCM. We observed that peak oxygen uptake was inversely related to LA dimensions and volumes and directly related to LAEF. These findings confirmed the previous observation that indices of LA function correlate with peak aerobic capacity in ICM and DCM. ${ }^{14)}$

It is well known that exercise intolerance is associated with a number of diverse mechanisms in patients with heart failure. The major determinant of peak exercise capacity in these patients, however, is the stroke volume response to exercise. ${ }^{15)}$ In normal subjects, stroke volume increases as a result of increased heart rate and myocardial contractility and as a result of increased LV diastolic volume by means of the Frank-Starling mechanism. ${ }^{16)}$ However, in patients with LV systolic dysfunction, maximal exercise cardiac output is primarily dependant on LV diastolic filling properties because of impaired myocardial contractility. ${ }^{17,18)} \mathrm{LV}$ diastolic filling is closely related to LV relaxation and elasticity and LA function. ${ }^{19,20)}$ In order to maintain stroke volume and cardiac output at a maximal level during exercise, LV diastolic filling should be at an optimum level. Maximal $\mathrm{O}_{2}$ uptake is reduced in patients with chronic atrial fibrillation, but the degree of the reduction is associated with underlying cardiac pathologic conditions. ${ }^{1)}$ The loss of an atrial contribution to ventricular filling and shortened ventricular filling time as a result of atrial fibrillation reduce exercise tolerance. However, atrial function plays only a minor role because cardioversion increases exercise capacity by about $5 \%$ in patients with atrial fibrillation. ${ }^{21)}$

The LA modulates LV diastolic filling and increases cardiac performance. ${ }^{22}$ During exercise, the LA reservoir and active pumping function are augmented, nevertheless, its conduit facilities remain unchanged. ${ }^{9)}$ To maintain LV filling at an optimum level during hemodynamic changes, the LA reservoir, conduit, and pumping function should work in harmony. It was reported that the LA contribution to LV filling increased as a compensatory mechanism in patients with asymptomatic or mildly symptomatic DCM, and therefore, stroke volume was relatively maintained. ${ }^{5}$ In patients with severe heart failure, compensatory LA contraction is decreased as a result of increased workload imposed on the LA myocardium due to increased LV diastolic wall stress and intrinsic LA dysfunction., ${ }^{9}$,3) Decreased LA function and increased LA dimensions are associated with decreased exercise capacity. ${ }^{24)}$ The results of this study indicate that LAEF and LA sizes are significantly related to peak oxygen uptake. Preserved LA function 
was a strong predictor of exercise capacity. In addition, the present study showed that peak oxygen uptake is significantly correlated with the peak A wave velocity, peak E wave deceleration time, E/A ratio, IVRT, and LVEF. This is consistent with recent studies demonstrating that LV diastolic rather than systolic function has an important role in determining exercise performance in patients with $\mathrm{CHF}^{3,4,25)}$

Many studies have described the contribution of LA function to LV diastolic filling. The LA acts as a reservoir during left ventricular systole, and maintains passive filling during early diastole and active pumping during late diastole. ${ }^{26-28)}$ In patients with LV dysfunction, the LA contribution to LV filling becomes more important. ${ }^{29,30)}$ In the early stages of LV systolic dysfunction, early ventricular diastolic inflow is decreased, and consequently atrial passive emptying is decreased and atrial active pumping function in late diastole is increased. ${ }^{8)}$ In this way, the LA reservoir, conduit, and pumping functions are reorganized and thus cardiac output is maintained. ${ }^{31)}$ As heart failure progresses, LA function decreases as a result of increased afterload on the LA myocardium. ${ }^{32)}$ In time, LA intrinsic dysfunction develops. LA pressure and volume overload lead to up-regulation of $\beta$-myosin heavy chain in the left atrial wall. This change reduces LA contraction velocity. ${ }^{33)}$ In an experimental study on six mongrel dogs, isolated atrial or ventricular, and combined dysfunction were created with atrioventricular ablation, and rapid atrial and ventricular pacing. ${ }^{26,27)}$ In dogs with atrial dysfunction but preserved left ventricular function, cardiac output was maintained within normal ranges because of a compensatory increase in LA conduit function. Also in isolated LV dysfunction, cardiac output was not significantly changed because of the compensatory increase in atrial booster pump function. Nevertheless, in dogs with combined LA and LV systolic dysfunction, rearrangement of the left atrial reservoir and conduit functions no longer compensates for the loss of systolic atrial function so cardiac output is decreased. ${ }^{27)}$

There are several mechanisms that explain the relationship between exercise capacity and LA function. LA function reflects left ventricular diastolic filling and therefore predicts the cardiac output and stroke volume response to exercise. ${ }^{24)}$ Reduced LA function may contribute to a decrease in LV preload and stroke volume according to the Frank-Starling mechanism. ${ }^{32,34)}$ Mean pulmonary arterial pressure increases more significantly after combined atrial and ventricular dysfunction in comparison with isolated atrial or ventricular dysfunction. ${ }^{7}$ Decreased right ventricular (RV) output as a result of increased RV afterload leads to decreased LV filling and cardiac output. ${ }^{35)}$

Study limitations: One possible limitation of our study involves the evaluation of LA function. We could not separately examine the contributions of passive and active atrial emptying to LV filling. LA contractile function may play a signifi- 
cant compensatory role in patients with LV dysfunction. ${ }^{27)}$ However, the purpose of this study was not to determine precise LA systolic function, but rather to determine global indices of LA function. ${ }^{8)}$ Second, the indices of LA function are influenced by loading conditions and LV diastolic function. LA contraction is augmented by increased venous return, however, LA distension beyond the peak length-action tension curve may be associated with atrial failure. ${ }^{36)}$ We investigated patients with heart failure due to ICM and DCM and an EF less than $40 \%$. We excluded patients with NYHA functional class IV and severe mitral regurgitation. Thus, our conclusions may not apply to these two groups and patients with impaired diastolic dysfunction and less severe or preserved LV systolic function.

In conclusion, our study has shown that there is a close correlation between peak oxygen uptake and LA function in heart failure. Left atrial sizes and ejection fraction, which can be easily obtained by routine echocardiography, may be useful as a predictor of exercise capacity in ICM and DCM.

\section{REFERENCES}

1. Ueshima K, Myers J, Ribisl PM, et al. Hemodynamic determinants of exercise capacity in chronic atrial fibrillation. Am Heart J 1993; 125: 1301-5.

2. Benge W, Litchfield RL, Macus ML. Exercise capacity in patients with severe left ventricular dysfunction. Circulation 1980; 61: 955-9.

3. Rihal CS, Nishimura RA, Hatle LK, Bailey KR, Tajik AJ. Systolic and diastolic dysfunction in patients with clinical diagnosis of dilated cardiomyopathy. Relation to symptoms and prognosis. Circulation 1994; 90: 27729 .

4. Davies SW, Fussell AL, Jordan SL, Pool-Wilson PA, Lipkin DP. Abnormal diastolic filling patterns in chronic heart failure - relationship to exercise capacity. Eur Heart J 1992; 13: 749-57.

5. Vanoverschelde JL, Raphael DA, Robert AR, Cosyns JR. Left ventricular filling in dilated cardiomyopathy: relation to functional class and hemodynamics. J Am Coll Cardiol 1990; 15: 1288-95.

6. Matsuda Y, Toma Y, Ogawa $\mathrm{H}$, et al. Importance of left atrial function in patients with myocardial infarction. Circulation 1983; 67: 566-71.

7. Hoit BD, Gabel M. Influence of left ventricular dysfunction on the role of atrial contraction: an echocardiographic-hemodynamic study in dogs. J Am Coll Cardiol 2000; 36: 1713-9.

8. Kono T, Sabbah HN, Rosman H, Alam M, Stein PD, Goldstein S. Left atrial contribution to ventricular filling during the course of evolving heart failure. Circulation 1992; 86: 1317-22.

9. Toutouzas K, Trikas A, Pitsavos C, et al. Echocardiographic features of left atrium in elite male athletes. Am J Cardiol 1996; 78: 1314-7.

10. Kurtoglu N, Akdemir R, Yuce M, Basaran Y, Dindar I. Left ventricular inflow normal or pseudonormal. A new echocardiographic method: diastolic change of left atrial diameter. Echocardiography 2000; 17: 653-8.

11. Sahn DJ, DeMaria A, Kisslo J, Weyman A. Recommendations regarding quantitation in M-mode echocardiography: results of a survey of echocardiographic measurements. Circulation 1978; 58: 1072-83.

12. Schiller NB, Shah PM, Crawford M, et al. Recommendations for quantitation of the left ventricle by twodimensional echocardiography. American Society of Echocardiography Committee on Standards, Subcommittee on Quantitation of Two-Dimensional Echocardiograms. J Am Soc Echocardiogr 1989; 2: 358-67. (Review)

13. Wasserman K, Hansen EJ, Sue DY, Whipp JB, Cosoburi R. Pathophysiology of Disorders Limihny Exercise. In: Harris Jm editor. Principles of exercise testing and interpretation. Malvern, 1994; 81-111.

14. Triposkiadis F, Trickas A, Pitsavos C, Papadopoulos P, Toutouzas P. Relation of exercise capacity in dilated cardiomyopathy to left atrial size and systolic function. Am J Cardiol 1992; 70: 825-7. 
15. Harringhton D, Coats AJ. Mechanisms of exercise intolerance in congestive heart failure. Curr Opin Cardiol 1997; 12: 224-32. (Review)

16. Sullivan MJ, Cobb FR, Higginbotham MB. Stroke volume increases by similar mechanisms during upright exercise in normal men and women. Am J Cardiol 1991; 67: 1405-12.

17. Dahan M, Aubry N, Baleynaud S, Ferreira B, Yu J, Gourgon R. Influence of preload reserve on stroke volume response to exercise in patients with left ventricular systolic dysfunction: a Doppler echocardiographic study. J Am Coll Cardiol 1995; 25: 680-6.

18. Tomai F, Ciavolella M, Crea F, et al. Left ventricular volumes during exercise in normal subjects and patients with dilated cardiomyopathy assessed by first-pass radionuclide angiography. Am J Cardiol 1993; 72: 1167-71.

19. Spes CH, Tammen AR, Fraser AG, Uberfuhr P, Theisen K, Angermann. Doppler analysis of pulmonary venous flow profiles in orthotopic heart transplant recipients: a comparison with mitral flow profiles and atrial function. Z Kardiol 1996; 85: 753-60.

20. Kihara Y, Sasayama S, Miyazaki S, et al. Role of the left atrium adaptation of the heart to chronic mitral regurgitation in conscious dogs. Circ Res 1988; 62: 543-53.

21. Ueshima K, Myers J, Morris CK, Atwood JE, Kawaguchi T, Froelicher VF. The effect of cardioversion on exercise capacity in patients with atrial fibrilation. Am Heart J 1993; 126: 1021-4.

22. Stefanadis C, Dernellis J, Toutouzas P. A clinical appraisal of left atrial function. Eur Heart J 2001; 22: 22-36. (Review)

23. Lavine SJ, Arends D. Importance of the left ventricular filling pressure on diastolic filling in idiopathic dilated cardiomyopathy. Am J Cardiol 1989; 64: 61-5.

24. Jikuhara T, Sumimoto T, Tarumi N, et al. Left atrial function as a reliable predictor of exercise capacity in patients with recent myocardial infarction. Chest 1997; 111: 922-8.

25. Lapu-Bula R, Robert A, De Kock M, et al. Relation of exercise capacity to left ventricular systolic function and diastolic filling in idiopathic or ischemic dilated cardiomyopathy. Am J Cardiol 1999; 83: 728-34.

26. Hoit BD, ShaoY, Gabel M, Walsh RA. In vivo assessment of left atrial contractile performance in normal and pathological conditions using a time-varying elastance model. Circulation 1994; 89: 1829-38.

27. Hoit BD, Gabel M. Influence of left ventricular dysfunction on the role of atrial contraction: an echocardiographic - hemodynamic study in dogs. J Am Coll Cardiol 2000; 36: 1713-9.

28. Boudoulas H, Starling RC, Vavuranakis M, et al. Left atrial volumes and function in orthotopic cardiac transplantation. Am Heart J 1995; 129: 774-82.

29. Sigwart U, Grbic M, Goy JJ, Kappenberger L. Left atrial function in acute transient left ventricular ischemia produced during percutaneous transluminal coronary angioplasty of the left anterior descending coronary artery. Am J Cardiol 1990; 65: 282-6.

30. Matsuda Y, Toma Y, Moritani K, et al. Assessment of left atrial function in patients with hypertensive heart disease. Hypertension 1986; 8: 779-85.

31. Prioli A, Marino P, Lanzoni L, Zardini P. Increasing degrees of left ventricular filling impairment modulate left atrial function in humans. Am J Cardiol 1998; 82: 756-61.

32. Dernellis JM, Stefanadis CI, Zacharoulis AA, Toutouzas PK. Left atrial mechanical adaptation to long-standing hemodynamic loads based on pressure-volume relations. Am J Cardiol 1998; 81: 1138-43.

33. Hoit BD, Shao Y, Gabel M, Pawloski-Dahm C, Walsh RA. Left atrial systolic and diastolic function after cessation of pacing in tachycardia-induced heart failure. Am J Physiol 1997; 273: H921-7.

34. Linderer T, Chatterjee K, Parmley WW, Sievers RE, Glantz SA, Tyberg JV. Influence of atrial systole on the Frank-Starling relation and the end-diastolic pressure-diameter relation of the left ventricle. Circulation 1983; 67; 1045-53.

35. Packer M, Lee WH, Medina N, Yushak M. Hemodynamic and clinical significance of the pulmonary vascular response to long-term captopril therapy in patients with severe chronic heart failure. J Am Coll Cardiol 1985; 6: $635-45$.

36. Williams JF Jr, Sonnenblick EH, Braunwald E. Determinants of atrial contractile force in the intact heart. Am J Physiol 1965; 209: 1061-8. 